\title{
LA TENSIÓN ENTRE SABER Y CREER EN MICHEL DE CERTEAU
}

\author{
JUAN D. GONZÁLEZ-SANZ
}

Universidad de Huelva

\begin{abstract}
RESUMEN: Michel de Certeau (Chambéry 1925-París 1986) fue un pensador jesuita francés que ha dejado una obra arriesgada y poliédrica, atravesada por la historia, la antropología, la lingüística y el psicoanálisis. Dentro de ella destaca su inconclusa antropología del creer, en la que se muestra cómo creer y saber son dos realidades humanas interconectadas, dos dimensiones interdependientes e inseparables. Este artículo profundiza en la relación polemológica que mantienen entre sí, conflictiva pero constante. Además, se examina cómo, desde el punto de vista de Certeau, el creer ocupa una posición de precedencia respecto al saber, realizando la función de un suelo imprescindible sobre el que poder edificar el conocimiento. Finalmente, a través de la referencia a sus estudios sobre la mística, se ha ido mostrando cómo nuestro autor contempla el modo en que saber y creer se relacionan y desarrollan de modo conjunto.
\end{abstract}

PALABRAS CLAVE: Michel de Certeau, conocimiento, creencia, tensión, mística.

\section{The conflict between knowledge and belief in Michel de Certeau's works}

\begin{abstract}
Michel de Certeau (Chambéry 1925-Paris 1986) was a French Jesuit thinker has left a brave and varied work, traversed by history, anthropology, linguistics and psychoanalysis. Within it stands the unfinished anthropology of belief, which shows how believing and knowing are two interconnected human realities, two dimensions interdependents and inseparables. This article explores the polemical relationship that keep each other, conflicting but steady. Furthermore, it examines how, from the point of view of Certeau, belief has a position of precedence over knowing, performing the function of an essential ground on which to build knowledge. Finally, through the reference to his study of mysticism, has been showing how our author contemplates how to know and believe relate and so set.
\end{abstract}

KEY WORDS: Michel de Certeau, knowledge, belief, conflict, mystic.

Michel de Certeau (1925-1986), pensador jesuita francés, ha desarrollado a lo largo de su obra una crítica original y valiente a las concepciones epistemológicas vigentes durante la segunda mitad del s. xx. Quizás la puesta en valor de la relevancia epistémica de la creencia sea la aportación certeauniana que mejor pone de manifiesto todas sus matizaciones y sugerencias frente a la forma tradicional de entender el conocimiento.

Este artículo busca ayudar al lector a identificar las razones de la insistencia de Certeau en esta relevancia del creer. Al tiempo, quiere provocar en quien lea estas páginas un cambio de perspectiva, que le lleve a incorporar las creencias (o, para evitar confusiones, el acto de creer) a su concepción del modo en que se produce el conocimiento. Se ofrece así, acompañando a Certeau, una oportunidad para integrar copulativamente creer y saber. Tomando conciencia de que el saber está siempre precedido y continuado por la creencia, el lector podrá pasar de un modelo de conocimiento estrecho (que por su soberbia pretensión de no necesitar de la creencia termina siendo manco y cojo), a un modelo epistémico ampliado con la añadidura del creer, lo que transformará tanto su punto de anclaje como sus expectativas últimas.

Esta invitación a cambiar de modelo epistemológico no se hace en el vacío, ni se señala un camino que no se ha transitado. Paso a paso, las páginas que siguen se dedicarán 
a mostrar el itinerario certeauniano entre creencia y saber. En un primer momento profundizando en el modo en que saber y creer se relacionan. Después exponiendo la principal característica del creer desde la óptica certeauniana: la debilidad. Finalmente, mostrando el peregrinar de nuestro autor por una tierra ignota y apasionante; por el lugar donde creencia y saber se mezclan de mil formas maravillosas, para dar como fruto las más inverosímiles palabras y experiencias; por el territorio de tantos hombres y mujeres que se han enfrentado con la realidad última de las cosas: el camino de la mística.

\section{SABER Y CREER, UNA INDISOLUBLE TENSIÓN}

Tras una lectura detenida de su obra es indudable que para Michel de Certeau el creer no solo no es algo menor en el campo del conocimiento, sino que acompaña en todo momento al saber; que se establece entre ellos una interrelación permanente y que no hay, en absoluto, una exclusión necesaria entre ambas áreas, sino todo lo contrario. Planteamiento coherente con el conjunto de la propuesta antropológica de nuestro autor, para quién no está nada clara la existencia de líneas divisorias entre las distintas facetas de lo humano, pero que supone la negación (o al menos la matización), de toda una serie de premisas fundamentales en lo relativo a la teoría del conocimiento y de la antropología clásicas.

Como, por ejemplo, aquella que viene ya desde Platón y aquella famosa línea que Sócrates propone a Glaucón dividir en cuatro partes y llamar «a la primera parte "ciencia", a la segunda "pensamiento", a la tercera "creencia" e "imaginación a la cuarta". Y a las dos últimas juntas "opinión" y a las dos primeras juntas "inteligencia” »". En esta poderosa e influyente reflexión, es central el orden entre las distintas partes, sosteniendo Platón que la creencia ocupa un lugar inferior al conocimiento (especialmente en cuanto a las cosas de mayor trascendencia, como la vida buena).

De hecho, en torno a la elección de este tipo de vida buena recomienda a Glaucón que valore que un argumento en este sentido «no hay que limitarse a creerlo, sino que hay que examinarlo muy bien, porque nuestro examen, estáte seguro de ello, apunta a lo más importante: una vida buena o mala $»^{2}$. Pese a reconocer que «tenemos desde niños, pienso, unas creencias acerca de lo justo y lo bueno, en las cuales hemos sido criados por nuestros padres, obedeciendo sus mandatos y honrándolas ${ }^{3}, \mathrm{y}$ a expresar que no se deriva nada bueno del abandono indiscriminado de estas creencias, la posición de Platón es claramente intelectualista, situando al conocimiento en el primer puesto de prioridad. En su concepción epistémica no hay apenas espacio para el creer "porque para quien el principio es lo que no sabe, y el final y la parte intermedia están trenzados a partir de lo que no se sabe, ¿qué medio habrá para que tal sucesión sea alguna vez ciencia?» ${ }^{4}$.

Son muchos los autores que al abordar la relación creer-saber han expresado posturas que, afines o no a la platónica, coinciden con ella en reducir o anular el papel epistémico de la creencia. Valga como muestra la siguiente afirmación, escrita por el

1 Platón, La República, trad. de Rosa Ma . Mariño Sánchez-Elvira, Salvador Mas Torres y Fernando García Romero, Akal, Madrid, 2009, 534a. Platón había indicado previamente esta división en 511e.

2 Ibid., $578 \mathrm{c}$.

3 Ibid., 538c.

4 Ibid., 533c. 
filósofo alemán de origen judío Leo Strauss y extraída de una carta suya a Eric Voegelin: "Cualquiera que sea el significado de noein desde luego no es pistis en ningún sentido» ${ }^{5}$.

Pero no es esta la posición de todos. Hay otra corriente de pensamiento que quiere integrar creer y saber. En un salto de siglos desde Platón, Miguel de Unamuno (cuya conexión espiritual e intelectual con Certeau sería muy interesante de estudiar ${ }^{6}$ ), cambia de tercio y plantea otro modo de relacionarse del saber y el creer. Da asiento de lo que ve como una relación polemológica, con una expresión, en mi opinión, muy cercana a los planteamientos certeaunianos: «Razón y fe son dos enemigos que no pueden sostenerse el uno sin el otro. Lo irracional pide ser racionalizado, y la razón sólo puede operar sobre lo irracional. Tienen que apoyarse uno en otro y asociarse. Pero asociarse en lucha, ya que la lucha es un modo de asociación» ${ }^{7}$.

También la postura certeauniana se centrará más en la dinámica conflictiva que se establece entre saber y creer que en una pretendida inferioridad del segundo respecto al primero. El primer paso de esta asociación conflictiva es una precedencia. De algún modo, según plantea Certeau, el creer precede en el tiempo al saber, es algo así como el suelo donde el saber crece. La psicoanalista Marie Balmary ha señalado también esta precedencia al afirmar que «en el espíritu, lo que no se espera no llega, lo que no se cree no puede aparecer, lo que se sabe «objetivamente» no puede desarrollarse» ${ }^{8}$.

El saber se identificaría así con cierto estancamiento, con una especie de techo de cristal que no permite el crecimiento, mientras que la creencia, alimentada por la falta de seguridad, se convierte en la tierra que nutre la evolución de lo conceptual, así como de lo espiritual. Profundizando en este tema insiste Balmary, como también haría Certeau con anterioridad, en la fundamental relevancia de las creencias que un grupo tiene sobre un individuo, que se convierten en una base esencial para el desarrollo de la persona, ya que «el hecho de ser creído, para un ser humano, es el carburante, la gasolina [...] ¿Hablaría, por ejemplo, si alguien no hubiera creído que podía hablar?»9.

La inspiración de la tradición judeocristiana y, concretamente, de las Escrituras, apoya con fuerza la orientación certeauniana sobre la precedencia del creer ${ }^{10}$. Múltiples referencias podrían dar cuenta de este apoyo, como aquella sentencia del profeta Isaías: «Si no creéis no comprenderéis» ${ }^{11}$. Certeau utilizará en varias ocasiones el recurso a la Biblia para seguir ahondando en la forma en que se produce esta precedencia. Entre ellas, destaca un ejemplo evangélico. Al morir Jesús, los apóstoles, perdido ya el tiempo de la visión directa, entran en un periodo especial en el que han desaparecido las muestras palpables de una realidad: el contacto directo con Jesús, al que identifican con el

5 Voegelin, E. y Strauss, L.: Fe y filosofía. Correspondencia 1934-1964, edición y traducción de Antonio Lastra y Bernat Torres Morales, Trotta, Madrid, 2009, p. 114.

6 Como Unamuno, creo que también Michel de Certeau podría decir de sí mismo que es «uno que afirma contrarios, un hombre de contradicción y de pelea, como de sí mismo decía Job: uno que dice una cosa con el corazón y la contraria con la cabeza, y que hace de esta lucha su vida" (UNAmUNo, M. DE: Sobre el sentimiento trágico de la vida, Alianza, Madrid, 2007, p. 266), o suscribir, con toda convicción, que "es la conducta, la práctica, la que sirve de prueba a la doctrina, a la teoría» (Ibíd., p. 268).

7 Ibid., p. 128.

8 Balmary, M.: Freud hasta Dios, trad. de Julia Argemí, Fragmenta, Barcelona, 2011, p. 28.

9 Ibid., p. 29.

10 En L'écriture de l'histoire, se encuentran muchos de los argumentos que Certeau pone sobre la mesa para justificar la idea de que la noción de creencia parece tener ciertas capacidades para iluminar el proceso por el que se puede llegar a un saber. Capacidades entre las que se encuentra poner en evidencia cómo parte de aquello que se dice saber, en realidad no puede decirse propiamente que se sepa, sino que se cree. Cfr. Certeau, M. DE: L'écriture de l'histoire, Gallimard, París, $2^{\mathrm{a}}$ ed., 1975, p. 4.

11 IsAíAs 7, 9. 
Mesías. En este nuevo tiempo ya no hay forma humana de construir una explicación racional para lo acontecido sin que se rompa esta convicción que ha habitado en ellos durante los tres años anteriores. Pero queda en ellos, aunque en un segundo plano si se quiere, la creencia de que todo lo vivido ha sido verdadero. Así, cuando todavía los apóstoles y los demás seguidores de Jesús no son capaces de dar razón de lo que ha supuesto su muerte, ya existe en ellos una fe que sostiene la coherencia de la experiencia precedente y cimenta la posibilidad del saber que llegará más tarde.

«Quizás esté aquí uno de los aspectos más característicos del Evangelio: los discípulos, los apóstoles, los testigos no llegan a comprender hasta después lo que les ha pasado. El sentido y la inteligencia vienen tras el acontecimiento como la audición del golpe tras la vista del gesto de golpear. Hay un retardo del entendimiento ${ }^{12}$.

De esta forma, el verdadero quid de la función que el creer puede tener como precursor, ampliación o complemento del saber, está en su capacidad de dar una oportunidad a la recepción de los acontecimientos. Nuestro autor parte de una concepción metafísica del ser humano atravesada radicalmente por la historicidad, ya desde los primeros compases de la elaboración de su antropología. Una historicidad que afecta a la persona hasta el punto en que desde ella no se puede afirmar la existencia de una verdad ajena a los condicionamientos que impone el transcurrir del tiempo humano. Por ello no extrañará que la capacidad del creer para facilitar la apertura al acontecimiento como fuente reveladora de lo real, sea una piedra de toque en su idea del hombre.

De ahí que el saber sea concebido por Certeau como algo limitado, que necesita de la ayuda del creer para poder hacerse cargo de la realidad. Sobre todo en la medida en que el saber padece una irresistible tendencia a configurarse como un proceder cerrado, continuo y transido de intereses ajenos al hecho de conocer (aunque habitualmente ciego a la influencia que sobre él tienen estos últimos). Es desde aquí, desde la radical importancia atribuida al acontecimiento histórico y a la capacidad del creer para darle cabida en la vida humana, desde donde se enarbola por parte de Certeau la objeción epistemológica fundamental sobre la concepción de un saber solitario.

«Elegimos, por tanto, un tipo de cultura, de verdad y más simplemente, de profesión, hacemos una elección global que desvela nuestras opciones personales, desde donde somos llevados por el acontecimiento a sostener, bajo formas más o menos sutiles y ocultas, esta proposición, en mi opinión, contradictoria: "Nosotros sabemos lo que pasa". Este saber niega por adelantado la posibilidad del objeto que pretende conocer; postula que nada puede ocurrir de forma diferente a como pensamos ya» ${ }^{13}$.

La paradójica distancia que en nuestro coexistir con el mundo nos aleja de él al intentar conocerlo, se convierte en la clave de la relación entre creer y saber. Si afirmamos que sabemos qué está pasando a nuestro alrededor, cerramos automáticamente nuestras posibilidades de recibir aquello que la realidad nos ofrece y que es inabarcable en su totalidad por nuestra limitada corporeidad. Solo la creencia, que supone asumir lo limitado de nuestro conocimiento, permite paradójicamente que este no se cierre tras la asunción de una primera idea sobre las cosas y sobre el mundo, sino que permanezca abierto a la complejidad de lo real.

12 Certeau, M. DE: L'etranger ou l'union dans la différence, nueva edición introducida y establecida por Luce Giard, Seuil, París, 2005 (1969), p. 4.

13 Certeau, M. DE: La prise de parole et autres écrits politiques, edición establecida y presentada por Luce Giard, Seuil, París, 1994 (1968), p. 54. 
El joven filósofo español David Pérez Chico lo ha expresado con claridad en uno de sus estudios sobre ese filósofo americano tan certeauniano que es Stanley Cavell, cuando afirma que «únicamente podemos salvar la distancia con los otros y con el mundo si aceptamos que nuestra relación con ellos (al menos en un nivel básico) no es una relación de conocimiento (si por conocimiento entendemos una creencia verdadera y justificada)» ${ }^{14}$. El mismo Cavell, en su obra Reivindicaciones de la razón, ahonda en el cuestionamiento del saber como piedra de bóveda de la antropología, pues en su opinión «la base de la criatura humana como un todo, su relación con el mundo tal cual es, no es la del conocimiento» ${ }^{15}$.

\section{LA DEBILIDAD DE CREER}

Michel de Certeau afirma la existencia de una relación polemológica entre creer y saber, y el establecimiento de una precedencia del primero sobre el segundo. Esta es una premisa básica de su teoría del conocimiento y su antropología del creer. Pero su corolario no será un enaltecimiento ciego de la creencia. Antes al contrario, para Certeau la principal característica del creer es la debilidad ${ }^{16}$. Ya desde escritos muy tempranos aparece este término en sus reflexiones sobre el tema, pero será con la compilación póstuma de estudios dedicados a la creencia realizada por Luce Giard y publicada en 1987, cuando «la debilidad de creer» tome todo su protagonismo dentro del pensamiento certeauniano ${ }^{17}$.

Una formulación posible de este principio es afirmar que creer es reconocer la propia debilidad, rechazando una fortaleza soberbia que situara al creyente en una dimensión más alta que la de otros. No es difícil percibir aquí qué enorme diferencia guarda esta perspectiva con otros modos, más tradicionales, de comprensión del creer. Quedan lejos de esta perspectiva certeauniana las afirmaciones que sostienen que el creyente (por ejemplo, el cristiano) tendría una posición superior al no creyente en todos los órdenes, desde el moral al epistemológico.

La asunción de la propia debilidad es algo esencial en Certeau, como reconoce Luce Giard al referirse a «la "debilidad" que tenía por emblema ${ }^{18}$, y que se extendía desde su autocomprensión como cristiano, hasta su ejercicio como historiador. También aquí, en el terreno de su competencia científica, en el lugar donde su autoridad podía haber sido presentada como indiscutible, nuestro autor marca una diferencia fundamental dejando aparecer poco a poco, en mil pequeños detalles, una «debilidad del historiador» ${ }^{19}$. Sus confesiones de incompetencia, de incapacidad para situarse en la posición de fuerza del que sabe con total seguridad, atraviesan toda su obra. Valga como muestra el párrafo que sigue, que hace referencia a su trabajo con los archivos históricos.

14 Pérez Chico, D.: «Filosofía sin lágrimas», en Lastra, A.: (ed.): Stanley Cavell, mundos vistos y ciudades de palabras, Plaza y Valdés, Madrid, 2010, p. 75.

15 Cavell, S.: Reivindicaciones de la razón, trad. de Diego Ribes, Síntesis, Madrid, 2003, p. 329.

16 Cfr. solo como ejemplo de muchas otras referencias, CERTEAU, M. DE: L'écriture de l'histoire, p. 372.

17 Certeau, M. DE: La faiblesse de croire, edición establecida y presentada por Luce Giard, Seuil, París, 1987.

18 Giard, L.: "Cherchant Dieu», en Certeau, M. DE: La faiblesse de croire, p. 18.

19 Giard, L.: «Un style particulier d'historien», en CERTEAU, M. DE: Le lieu de l'autre. Histoire religieuse et mystique, edición establecida por Luce Giard, Seuil/Gallimard, París, 2005, p. 12. 
«A fuerza de leer, pero sin poder entenderlas nunca, palabras que se refieren a experiencias, doctrinas o situaciones extrañas, yo veía alejarse progresivamente el mundo del que inventariaba los restos. Se me escapaba o más bien yo comenzaba a darme cuenta de que se me escapaba $»^{20}$.

Por otra parte, además de una apología de la debilidad como concepto y como realidad propia, hay en Certeau una reivindicación permanente de los débiles ${ }^{21}$. Les ha erigido un monumento en L'invention du quotidien, donde esta tendencia certeauniana a dar voz a los sin voz llega a su culmen ${ }^{22}$. Tanto es así que su trabajo sobre las prácticas cotidianas (y sobre las resistencias de los débiles), que desembocaría en la publicación de L'invention du quotidien, tuvo por intención primera, en palabras de Luce Giard, «la refutación de las tesis comunes sobre la pasividad de los consumidores y la masificación de las conductas» ${ }^{23}$.

Esta reivindicación de los débiles se despliega hasta llegar incluso a lo relativo al gusto estético, sosteniendo nuestro autor que por más pobre que se sea, todos y cada uno de los habitantes de la ciudad tienen derecho a tener su propia forma de valorar lo bonito o lo feo en base a sus propios criterios y no necesariamente en línea con lo que las élites dominantes establecen como el patrón de la belleza o la fealdad. Es otro modo de expresión de la ya clásica confrontación, falaz tantas veces según Certeau, entre una supuesta cultura y un supuesto gusto popular.

«Lo que se denomina "vulgarización” o "degradación” de una cultura sería entonces un aspecto, caricaturizado y parcial, de la revancha que las tácticas de uso se toman sobre el poder dominador de la producción $»^{24}$.

Por otra parte, con su afirmación de la debilidad de creer Certeau actualiza el discurso cristiano llevándolo a una renovada sencillez, a una kénosis que le hará afirmar que la experiencia cristiana está transida (o ha de estarlo si quiere ser sincera) de este reconocimiento de la propia debilidad.

«La fe cristiana es experiencia de fragilidad, medio de convertirse en huésped de otro que inquieta y que hace vivir. Esta experiencia no es nueva. Después de los siglos, los místicos, los espirituales la viven y la narran. Actualmente he aquí que se hace colectiva, como si todo el cuerpo de las Iglesias, y no ya algunos individualmente heridos por la experiencia mística, debiera vivir lo que el cristianismo ha anunciado siempre: Jesucristo ha muerto. Esta muerte no es solamente el objeto de un mensaje concerniente a Jesús, sino la experiencia de los mensajeros. Las Iglesias, y no solamente el Jesús del que hablan, parecen llamadas a esta muerte por la ley de la historia. Se trata de aceptar ser débil» ${ }^{25}$.

\footnotetext{
20 Certeau, M. DE: Histoire et psychanalyse entre science et fiction, Gallimard, París, 2002 (1987), p. 189.

21 Esta reivindicación afecta a todos los campos y a todas las épocas, pues, como dirá Giard, «los mecanismos de resistencia son los mismos de una época a otra, de un orden a otro, ya que el mismo reparto desigual de fuerzas subsiste y los mismos procesos de desvío sirven al débil como último recurso", Giard, L.: "Histoire d'une recherche», en Certeau, M. DE: L'invention du quotidien.1. Arts de faire, Gallimard, Folio Essais, París, 1990, p. XIV. Véase, como ejemplo de una actitud permanente, el rescate de la importancia de R. Gaultier, traductor (débil, mediocre, olvidado) de San Juan de la Cruz, en CERTEAU, M. DE: L'Absent de l'histoire, pp. 48, 70.

22 Certeau, M. de; Giard, L. y Mayol, P.: L'invention du quotidien. II. Habiter, cuisiner, Gallimard, nueva edición revisada y aumentada, presentada por Luce Giard, París, 1994 (1980), pp. 199ss.

23 GIARD, L.: «Histoire d'une recherche», p. XXIV.

24 Certeau, M. DE: L'invention du quotidien. I. Arts de faire, pp. 54s.

25 Certeau, M. DE: La faiblesse de croire, p. 304.
} 
Este mensaje, completamente a contracorriente de las líneas de pensamiento mayoritarias de la Iglesia católica en su tiempo y también ahora, es coherente y natural en Certeau desde el momento en que toma en consideración la seriedad del concepto de desencantamiento, reflejo de una situación muy difícil para la fe cristiana en el seno de la sociedad occidental ${ }^{26}$. Peter Sloterdijk ha formulado certeramente cómo esta situación es la consecuencia de una creencia generalizada durante un tiempo histórico concreto, la creencia de que «Dios no sólo renuncia en este momento a su capacidad de encarnarse en un hombre en singular, también pierde de manera visible todo interés en manifestarse a través de determinados individuos» ${ }^{27}$.

Tras esta idea de desencantamiento se esconde la pérdida de un sentido común de la trascendencia en el que sostener el cosmos. Una vez desencantado, el mundo queda en silencio, pues «no está atravesado por la voz» ${ }^{28}$. Pero en ese silencio persiste, no obstante, «la creencia de que debe haber voces $»^{29}$ y esa creencia produce la aparición de numerosos candidatos para sustituir al Dios que con su Palabra, permitía antaño comprender de forma total la realidad. Entre los que quieren ocupar su puesto la ciencia pretende tomar un lugar primero, pero sus sacerdotes, los científicos, no pueden tomar a título propio el lugar de la voz vacante, pues como señala Certeau es propio de la ciencia el renunciar al nombre propio, a la voz humana personal y reconocible. La ciencia sana es, a buen seguro, el dominio de lo impersonal, hasta el punto en que según nuestro autor, «el locutor humano está excluido: llega a ser científica una proposición que es independiente de su enunciador» ${ }^{30}$.

Presente ya desde sus primeros textos este cambio en la percepción del mundo, lejos de ser para él algo negativo, esconde en su interior la posibilidad de mostrar a la fe su propia debilidad y así abrirla a su verdadera dimensión.

«Este desencantamiento, debido a un reencuentro con los otros y a una confrontación con la realidad de la que pretendemos hablar, nos abre precisamente la vía de una más auténtica verdad humana y evangélica. "Cuando soy débil, entonces soy fuerte" $\left(2\right.$ Cor. 12, 10)» ${ }^{31}$.

Queda claro pues que aunque Certeau está definitivamente abierto a lo que las creencias (y, por tanto, también una fe concreta) pueden aportar en el esfuerzo epistémico del hombre, no por eso se sitúa en la posición de quien afirma que la fe cristiana es por sí misma garantía de un mayor acceso a la verdad. Para él se hace nítido que nada puede quedar ajeno a un examen crítico — tampoco la fe—, y que éste ha de hacerse con los

26 Vigarello, G.: «Entretien avec Michel de Certeau», Esprit, febrero 1982, p. 185. Nótese que tomar en cuenta no quiere decir compartir este planteamiento. A pesar de que no es el objeto de estas páginas, conviene hacer referencia a dos obras que abordan esta cuestión del desencantamiento con especial interés y amplitud, que debemos a Marcel GaUchet, El desencantamiento del mundo, trad. de Esteban Molina, Trotta, Madrid, 2005; y a Richard DennetT, Romper el hechizo, trad. de Felipe de Brigard, Katz, Madrid, 2007. Debo a Antonio Lastra que me haya hecho llegar hasta Marcel Gauchet, al que considera el «mayor teórico de lo que él mismo ha llamado "la salida de la religión" o, siguiendo a Max Weber, "el desencantamiento del mundo" ", LASTra, A: La filosofía y los dioses de la ciudad, Aduana Vieja, Valencia, 2011, p. 81. Certeau, por otra parte, hará referencia a la presencia de esta cuestión en Descartes, Weber o Merleau-Ponty, entre otros, cfr. Certeau, M. DE: La faiblesse de croire, pp. 44, 51; Le lieu de l'autre, p. 302; La prise de parole, p. 111.

27 SloterdikJ, P.: El desprecio de las masas. Ensayo sobre las luchas culturales de la sociedad moderna, trad. de Germán Cano, Pre-textos, Valencia, 2002, p. 83.

28 Vigarello, G.: «Entretien avec Michel de Certeau», p. 185.

29 Ibidem.

30 Ibidem.

31 Certeau, M. DE: «La parole du croyant dans le langage de l’homme», Esprit, octubre 1967, p. 465. 
instrumentos de los que disponemos. De este modo, hay que «encontrar en la duda el lugar de un trabajo o de una tarea de la fe» y, en el análisis de esta fe «debemos considerar como una tentación el rechazo (o perezoso o cobarde) de las técnicas y las investigaciones que nos permitirán "hacer la verdad" para "llegar a la luz" ${ }^{32}$.

Como consecuencia de esta arriesgada asunción de la propia debilidad no son pocos los autores que han visto en la obra certeauniana una consideración cuasi-relativista del hecho cristiano, que llega a su cenit cuando Certeau plantea la necesidad de no considerar el cristianismo como algo universal y que, en este sentido, la fe cristiana concreta no puede aspirar a ser algo común a cualquier hombre ${ }^{33}$.

\section{La MÍstica, UN NO-SABer QUe NACE DEL CREER}

La obra culminante de Michel de Certeau y su último libro publicado en vida fue $\mathrm{La}$ fable mystique, un estudio denso y original sobre el fenómeno místico. En sus páginas queda establecida la descripción certeauniana de la relación que guardan entre sí el creer y el saber, de la manera más acabada que llegó a tener. Según Giard, este texto será para Certeau su "libro más amado» ${ }^{34}$, en el que se condensa todo lo aprendido a lo largo de una intensa vida consagrada al estudio. Reuniendo y ampliando en un conjunto bien hilado multitud de textos anteriores y otros nuevos, Certeau dio a la luz esta obra en 1982, con la intención de que fuera la primera entrega de un conjunto final de dos volúmenes. Las múltiples ocupaciones primero y finalmente la enfermedad que habría de llevarle a la tumba impidieron que el segundo tomo llegara a aparecer ${ }^{35}$.

El tema que se aborda aquí, la mística, es uno de los dos temas clave para Certeau ${ }^{36}$, que tiene que atravesar distintos saberes para buscar una aproximación certera a las cuestiones que esta le plantea. Nuestro autor nunca pidió permiso para realizar sus incursiones en el mundo de la mística. Leyó, estudió y publicó cuanto quiso, dentro y fuera de la historiografía: "Se desplazaba de un saber a otro por necesidad, para seguir una cuestión nacida en otro campo, dónde le parecía que no había recibido un trato satisfactorio ${ }^{37}$.

Entusiasmado por su ansia de un conocimiento veraz, esta itinerancia metodológica le llevaba a huir de encasillamientos disciplinares o académicos, pero no por el afán de estar a la moda de la interdisciplinariedad, sino por la propia necesidad de saber, ya que «esta libertad de movimiento estaba al servicio de un trabajo de investigación preciso, exigente ${ }^{38}$. Ocurre pues, con el Certeau que se apasiona con la mística, como con el Freud que «se autoriza así a atravesar con su aparato analítico las disciplinas que

32 Ibid., p. 459.

33 RoyannaIs, P.: "Michel de Certeau: l’anthropologie du croire...», en Recherches de Sciences Religieuses 91/4 (2003), p. 520. Fundamental la idea de que «el cristianismo es un fenómeno limitado», Certeau, M. de; Domenach, J.-M.: El estallido del cristianismo, trad. de Miguel de Hernani, Sudamericana, Buenos Aires, 1974, p. 64.

34 Giard, L.: «Cherchant Dieu», p. 20.

35 En alguno de sus artículos de aquellos años, Certeau llegó a anunciar la publicación de dicho tomo, cfr. Certeau, M. DE: La faiblesse de croire, p. 222 n. 26. Luce Giard afirmaba en 1987 estar trabajando en su publicación póstuma, proyecto que finalmente no se concluyó, cfr. GIARD, L.: «Cherchant Dieu», p. 7.

${ }_{36}$ Giard, L.: «Un chemin non tracé», en CERTEAU, M. DE: Histoire et psychanalyse entre science et fiction, p. 21.

37 CERTEAU, M. DE: Histoire et psychanalyse entre science et fiction, p. 13

38 GIARD, L.: «Un chemin non tracé», p. 19. 
se han repartido los fenómenos psíquicos según una diferencia (entre "individuales" y "colectivos") que precisamente él rechaza y que intenta transformar» ${ }^{39}$.

Por ello, como todos los textos certeaunianos, La fable mystique se presenta a sus lectores como un fresco abigarrado, en el que la multitud de detalles y lo arriesgado de los trazos invitan a una lectura sosegada y atenta ${ }^{40}$. También aquí la mirada multifocal sobre un mismo asunto es la orientación metodológica clave, de forma que se encontrará el lector secciones de gran contenido histórico, pero también sociológico, antropológico o teológico, y casi destacando sobre el resto, importantes reflexiones de carácter lingüístico. La relevancia del lenguaje como principal vía de entrada de Certeau en el fenómeno místico, queda ya reflejada en el título de la obra con la referencia a la fábula. Pero llegó a ser incluso más explícita en versiones anteriores del título, pues tal y como se recoge en la mancheta de L'Absent de la histoire, publicada en 1973, la obra que nos ocupa iba a llamarse en un primer momento Le langage mystique ${ }^{41}$.

Pero, ¿por qué puede decirse que su estudio sobre la mística sirve para ejemplificar la teoría certeauniana de que el creer y el saber están en interrelación? Básicamente, porque de sus páginas, acendrada como una pepita de oro entre la arena del río, puede extraerse la conclusión de que la mística abre una nueva relación con las posibilidades de comprender la realidad.

\subsection{La puerta a un saber que desborda lo previsto}

A lo largo de los tiempos algo común a las diferentes corrientes espirituales que podrían ser identificadas como místicas sin faltar a la verdad, es que el conocimiento que deriva de la experiencia religiosa «obedece a otro tipo de coherencia distinta a la del discurso filosófico» ${ }^{42}$. Por ello, la mística abre una vía hacia un nuevo saber a través de dos aportaciones clave: el cuestionamiento del saber establecido y la realización de una propuesta de enriquecimiento del mismo.

En primer lugar, la mística afirma el no saber. El místico ${ }^{43}$ una y otra vez, más allá de la religión donde hunda sus raíces o del tiempo en el que viva, prescinde de lo necesario para ser sabio a ojos del mundo. Su afirmación de Dios parte de la negación de lo sabido sobre Él y no deja de cuestionar cualquier saber que pudiera aparecer como definitivo ${ }^{44}$.

«Se convierte en "místico" todo objeto — real o ideal-, del que la existencia o la significación escapa al conocimiento inmediato» ${ }^{45}$.

Así, si se afirma la existencia de Dios y se sostiene, como harán los místicos, que la unión con Él es el fin último de la existencia, y al mismo tiempo se niega más o menos vehementemente lo que la Iglesia afirma sobre lo divino, la soledad y el hambre de respuestas se hacen presentes y no queda más que iniciar una búsqueda radical de

39 CERTEAU, M. DE: Histoire et psychanalyse entre science et fiction, p. 91.

40 Por su complejidad y su riqueza, pueden aplicarse a esta obra las palabras de Paul Klee que Certeau recuerda frente a El jardín de las delicias, de El Bosco: «La obra plástica presenta para el profano el inconveniente de no saber por dónde comenzar, pero, para el aficionado advertido, la ventaja de poder variar ampliamente el orden de lectura y tomar así conciencia de la multiplicidad de sus significaciones», Paul Klee citado en Certeau, M. DE: La fable mystique, 1. XVIe-XVIIe siècle, Gallimard, París, 1982, p. 73.

41 Certeau, M. De: L'Absent de l'histoire, París, Mame, 1973, p. 1.

42 Certeau, M. DE: La faiblesse de croire, p. 216. Una ampliación de la relación entre filosofía y mística puede verse en CERTEAU, M. DE: Le lieu de l'autre, pp. 339s.

43 Me referiré a todos ellos así, hombres o mujeres, para evitar la confusión con el sustantivo mística.

44 Certeau, M. DE: El estallido del cristianismo, p. 32.

45 Certeau, M. DE: La fable mystique, p. 132. 
Dios. Concretamente, en la mística católica de los siglos XVI y XVII (la más profundamente estudiada por Certeau), la clave de esta búsqueda es un elemento comunicativo. Si Dios habla pero ya no se le escucha, no quedará más remedio que volver a «aprender a escuchar» ${ }^{46}$.

Negar, por tanto, es el primer paso de la mística. Negar primordialmente el silencio de Dios. Negar que el discurso eclesiástico y teológico sea capaz de expresar con plenitud lo que Dios quiere comunicar a los hombres. Negar también la incapacidad de la humanidad para escuchar la Palabra de Dios. Por ello, quien se adentra en la mística pone toda su fuerza en un no: no al dominio conceptual sobre una realidad inabarcable; no al corsé de una experiencia lastrada por la ausencia de riesgo; no a la tentación de escapar a la dificultad huyendo de la confrontación con los otros. En los místicos, como ha ocurrido tantas veces después, en multitud de resistencias no violentas frente a poderes abusivos, «la no-cooperación es la acción inicial, una ruptura instauradora» ${ }^{47}$.

De antigua tradición en el cristianismo esta negación de la validez del conocimiento establecido, del saber oficial sobre Dios y todo lo relativo a lo divino, llevará a los místicos a la paradójica afirmación de que la verdadera sabiduría sobre las cosas más importantes (y sobre la más importante de todas las cosas), se encuentra lejos de sus pretendidos detentadores y habita en los rincones más inesperados. La cantera de la Biblia sustentará por doquier su discurso, bien sea recurriendo a los profetas como Isaías ( «Fracasará la sabiduría de sus sabios y se eclipsará la prudencia de sus prudentes» ${ }^{48}$ ); a los Evangelios ( «Te alabo, Padre, Señor de cielo y tierra, porque, ocultando estas cosas a los entendidos, se las diste a conocer a la gente sencilla» ${ }^{49}$ ), o a las cartas de Pablo ${ }^{50}$.

Es el momento en que se pone en juego la noción de docta ignorancia ${ }^{51}$, con la que los místicos ensalzarán la sabiduría de los sencillos, aquellos a los que Henri Bremond (el gran historiador de la espiritualidad francesa) llamaba " "pequeñas almas” grandes por su sabiduría oculta ${ }^{52}$. Representado por diferentes personajes en las obras de los místicos, a través de las distintas épocas y geografías (el pastor, el campesino, el vagabundo, etc.), la figura de una persona de origen humilde y carente de toda instrucción, "puro de todo saber y de todo interés ${ }^{53}$, se presenta como la depositaria del mensaje divino, tanto por su comunicación personal con Dios como por su capacidad para interpretar lo que ha recibido de Él.

Por ello los místicos, más allá de su propia condición, de su nivel social y de sus ocupaciones, buscarán la cercanía de estos sabios sencillos, en los que esperan encontrar el acceso a lo divino que les niegan los libros y las estructuras de la Iglesia. Certeau

46 Ibid., pp. 218ss.

47 Certeau, M. DE: La prise de parole, p. 145. Es evidente aquí la referencia a la llamada teología negativa, estrechamente asociada a la figura del Pseudo-Dionisio Areopagita, teólogo cristiano del siglo v. Su idea principal es que no es posible para el hombre afirmar nada sobre lo que Dios es, pero sí sobre lo que no es.

48 Isaías 29, 14. Cfr. Certeau, M. DE: L'écriture de l'histoire, p. 452 n.9.

49 Mateo 11, 25. Cfr. Certeau, M. DE: La fable mystique, p. 320.

50 PaBlo, $1^{a}$ Corintios $1,18-31$.

51 En la obra certeauniana éste no es, de ningún modo, un concepto menor, ya que desde sus estudios históricos a sus análisis sobre los campus universitarios franceses de los 70 , la referencia a la sabiduría que habita en lo sencillo y desafía las normas rígidas de las estructuras cerradas, es algo mil veces presente (cfr. por ejemplo, CERTEAU, M. DE: La culture au pluriel, Seuil/C. Bourgois Éditeur, nueva edición establecida y presentada por Luce Giard, París, 1993 (1974), pp. 96ss.). En L'invention du quotidien. 1. Arts de faire, pp. 82-96, puede verse, además, un abordaje del modo en que Pierre Bourdieu utiliza la expresión docta ignorancia en sus estudios socio-antropológicos.

52 Certeau, M. DE: L'Absent de l'histoire, p. 41.

53 Certeau, M. DE: La fable mystique, p. 353. 
presentará a Pierre Favre, uno de los primeros compañeros jesuitas de San Ignacio, como alguien que «gusta de las devociones universales y sencillas. Así este hombre cuyas relaciones se extienden a los grandes personajes del momento y cuya correspondencia está plagada de hombres célebres, prefiere para la conversación íntima a las pequeñas gentes [...] tales son los amigos de su meditación $»^{54}$. Igual ocurrirá con su admirado Surin: «Este hombre de ciudad y espiritual descubre en los pueblos y en las gentes humildes el testimonio conmovedor del Espíritu» ${ }^{55}$.

Los místicos mismos, identificándose con estos «pequeños santos», se esforzarán en mil ocasiones por abandonar todo aquello que está en la línea de lo social, teológica o eclesialmente bien valorado, para optar por caminos de sencillez y de abajamiento. La máxima que los guía la expresó poéticamente San Juan de la Cruz de manera inigualable, con aquel "para venir a lo que no sabes, has de ir por donde no sabes» ${ }^{56}$.

Así pues, el místico es capaz de abrir nuevos caminos que dejan atrás los límites del conocimiento previo y lo hace — como el iletrado iluminado de Surin o el rabino Akiba que siendo «un ignorante pastor, llegó a ser uno de los mayores sabios de su generación ${ }^{57}$ - prescindiendo de las garantías que la sociedad se da para acreditar una sabiduría. Scholem ha dejado claro hasta qué punto puede llegar este descrédito frente al saber, pues «lo que para el místico es una profunda intuición, un gran símbolo, aparece a los ojos más sobrios de los historiadores del pensamiento o de los filósofos como un malentendido de concepciones filosóficas. Pero precisamente en esos malentendidos demuestran tales concepciones su esencia productiva en la historia de la religión y aseguran la continuidad del universo lingüístico, a cambio, eso sí, de su credibilidad» ${ }^{58}$.

Esta «esencia productiva» a la que se refiere Scholem es el segundo aspecto a través del que la mística da pie a un nuevo saber. Porque para ella no se trata de una negación de lo conocido y punto final. Es cuestión también, en un segundo momento, de proponer a través de la creencia otra forma de conocer la realidad circundante, de enriquecer el saber.

Entre nosotros Unamuno lo ha afirmado con fuerza: «El creer es una forma de conocer, siquiera no fuese otra cosa que conocer nuestro anhelo vital y hasta formularlo. Solo que el término creer tiene en nuestro lenguaje corriente una doble y hasta contradictoria significación, queriendo decir, por una parte, el mayor grado de adhesión de la mente a un conocimiento como verdadero, y de otra parte una débil y vacilante adhesión. Pues si en un sentido creer algo es el mayor asentimiento que cabe dar, la expresión "creo que sea así, aunque no estoy de ello seguro» es corriente y vulgar» ${ }^{59}$.

Esta dimensión enriquecedora de la creencia respecto del saber es algo común en la tradición mística occidental, tanto cristiana como judía. Respecto a esta última son

54 Certeau, M. DE: «Introduction» al Mémorial (Favre), Desclée de Brouwer, París, 1959, p. 14.

55 Certeau, M. DE: «Introduction» a Guide Spirituel (Surin), Desclée de Brouwer, París, 1963, p. 15. La importancia de Surin para Certeau es enorme, algo notorio en toda su obra. Para nuestro autor, en Surin, «ese D’Artagnan de la mística» (La possession de Loudun, Gallimard, París, 1970, p. 364), se aprecia un «estilo» especial («Introduction» a Correspondance (Surin), Desclée de Brouwer, París, 1966, pp. $55,57,66,84)$, así como una inestabilidad más violenta y continua que en otros místicos (Ibíd., p. 54). Como una pequeña muestra de este gran respeto que le profesa, véase que cuando Certeau escribe un artículo sobre la mística para un diccionario, la única cita textual que incluye es de Surin, cfr. Le lieu de l'autre, p. 337.

56 JuAn De la CRUZ: «Subida al Monte Carmelo», Obras completas, BAC, Madrid, 11ª ed., 1982, p. 125.

57 Scholem, G.: Conceptos fundamentales del judaísmo, trad. de José Luis Barbero, Trotta, Madrid, $3^{\mathrm{a}}$ ed., 2008, p. 75.

58 Ibid., p. 58.

59 UnAmuno, M. DE: Sobre el sentimiento trágico de la vida, p. 200. 
buenos exponentes de la presencia de esta concepción en el misticismo judío la posición incluyente entre creencia y saber que defiende Martin Buber ${ }^{60}$, así como el conjunto de la obra del ya citado Gershom Scholem. En su libro Conceptos fundamentales del judaísmo, este último expresa el desbordamiento que produce la mística en el saber cuando afirma, sobre el Dios de los místicos, que «nunca está allí donde uno estaría más inclinado a buscarlo; siempre está más allá. Más allá de la vida, más allá del puro ser, incluso, contra Platón y Aristóteles, más allá del pensamiento» ${ }^{61}$. El historiador hebreo, gran conocedor de la tradición mística judía (y también cristiana e islámica), sostiene que las aportaciones de cada una de estas tradiciones van abriendo camino para el pensamiento, planteando cuestiones que el discurrir por sí mismo no habría abordado ${ }^{62}$.

\subsection{La mística rompe las fronteras de la teología}

La apertura mística de una nueva vía de conocimiento, a través de la negación y del enriquecimiento que se han tratado anteriormente, tendrá repercusiones en el campo general del saber. No obstante, la primera disciplina que se verá afectada por sus cuestionamientos será la teología, el discurso racional sobre la fe que los místicos desbordan.

La situación de la teología a mediados del s. xvi es planteada brevemente por Certeau como la de una disciplina escindida.

«El cisma progresivo entre una ciencia que ya no es el discurso verdadero de una revelación histórica y una experiencia que se separa de la teología para describirse aisladamente, se manifiesta en cada expresión de la vida cristiana [...] la noción de teología se modifica; ya no define la ciencia rigurosa de las realidades de la fe, sino el sentimiento del misterio que se da en la experiencia, una sabiduría impregnada de piedad y madurada por el discernimiento, reflexión de un tipo particular, nacida y dedicada a la relaciones personales con Jesucristo y las actitudes morales a las que estas llevan» ${ }^{63}$.

Para entender la posibilidad de que se consolidara en los siglos XVI y XVII una corriente como la mística (capaz de realizar un serio ataque en la línea de flotación de la otrora omnipotente teología), no puede dejar de resaltarse la importancia de factores que desde muy atrás venían favoreciendo un profundo cambio conceptual y cultural dentro del cristianismo. Entre ellos destacan diferentes planteamientos que van poniendo en duda, ya desde el siglo xv y aún más atrás, la «legibilidad» del mundo, la posibilidad de ver directamente en las cosas la huella de la Providencia divina ${ }^{64}$. Es el caso del nominalismo coadyuvante esencial para la revolución epistémica de la mística. Como dirá Certeau, "el ockamismo ha exiliado del discurso su verificación última» ${ }^{65}$, debido a que "para Ockam la teología ya no puede ser una verdadera ciencia» ${ }^{66}$.

60 La concepción profundamente dialógica de Martin Buber sobre la realidad humana no anda muy lejos del pensamiento de Certeau, como puede verse en Buber, M.: Yo y Tú, trad. de Carlos Díaz, Caparrós Editores, Madrid, $4^{\mathrm{a}}$ ed., 2005, pp. 15, 63.

${ }_{61}$ Scholem, G.: Conceptos fundamentales del judaísmo, p. 14.

62 Ibid., p. 57.

63 Certeau, M. DE: «Introduction» al Mémorial (Favre), p. 25.

64 Certeau, M. DE: La fable mystique, p. 84.

65 Ibid., p. 47.

${ }^{66}$ Ibid., p. 126. Cfr. también Ibíd., p. 173. Otro erudito jesuita, en este caso español, Ricardo GarcíaVilloslada, ya había señalado al ockamismo como un factor predisponente imprescindible en el surgimiento del pensamiento teológico de Lutero, cfr. García-VILloslada, R.: Martín Lutero. El fraile hambriento de Dios, BAC, Madrid, 1973. Certeau afirmará que este proceso de cuestionamiento de la teología iniciado con Ockam, culminará con la separación definitiva de la teología y la filosofía en 1641, a raíz de la publicación del Augustinus de Jansenio, donde éste «afirma la incompatibilidad de la filosofía, fundada sobre 
Pero no son solo objeciones teóricas las que la mística pone a la teología. También con su ejemplo práctico niega la exclusiva competencia de la teología y de los teólogos para hablar sobre Dios. De diversas procedencias intelectuales y académicas, los místicos se atreven a pronunciarse sobre las cuestiones más intrincadas, sobre las cosas de Dios y su mensaje, sin tener el respaldo firme de una titulación teológica, de una corporación universitaria o de un cargo ministerial. Humanistas, políticos, religiosas, o incluso simples legos, desafían con sus palabras y sus escritos el coto vedado que la teología había erigido en torno de lo divino, dudando de la capacidad epistémica de la teología para presentar realmente a Dios a su pueblo ${ }^{67}$. Al abordar las preguntas sobre Dios sin orejeras el místico desborda la teología, pues «trata una cuestión transversal en relación a las disciplinas establecidas ${ }^{68}$.

Además, la negación mística del saber teológico al uso implica el rechazo de una premisa que ha sido siempre el sostén del edificio teológico (al menos en la Iglesia católica): la imposibilidad de un acceso directo y general a la comunicación con Dios. La teología clásica ponía como condición básica para el establecimiento de esta comunicación con Dios, es decir, para comprender su Palabra, la interpretación autorizada de los sacerdotes. Solo ellos, después de una pléyade de estudios realizados en el marco de la enseñanza eclesiástica (y con una orientación siempre afín al Magisterio de la Iglesia), tenían la capacidad de hablar verdaderamente de las cosas divinas. Frente a esta línea, Lutero basará gran parte de su reforma teológica en la capacidad individual de cada cristiano de llegar a conocer a Dios a través de la lectura de las Escrituras. Como tercera vía alternativa la mística erigirá en condición para comprender a Dios no ya tanto un conocimiento sino una experiencia.

Poco a poco, lo que empieza siendo una orientación más o menos espiritual dentro del mismo campo de la teología o del pensamiento cristiano (la mística es entonces un adjetivo que se añade a diferentes conceptos y cuestiones), terminará convirtiéndose en toda una disciplina autónoma. Es el momento en que la mística se vuelve sustantiva ${ }^{69}$. A partir de entonces, con uno u otro nombre, participa como una más en el nuevo juego de las teologías múltiples ${ }^{70}$, dentro del triángulo que formarán teología escolástica, teología mística y teología positiva. Para Certeau, esta ruptura de la «arquitectura única de "la" teología», entraña una «espacialización del saber» en función de una «organización de la sociedad en espacios diferentes relativos a relaciones de fuerza (políticas, jurídicas o retóricas) y no ya, esencialmente, a las jerarquías de clases o estados ${ }^{71}$. Como Certeau ha dejado claro en sus estudios, el saber siempre está condicionado por los lugares donde se produce.

el "intelecto", con la teología, fundada sobre la "memoria", es decir sobre la autoridad de la Escrituras y de los Padres», Certeau, M. DE: La fable mystique, p. 146.

67 El itinerario espiritual de Ignacio de Loyola es un claro testimonio de esta afirmación. Investigado varias veces por las autoridades eclesiásticas por su manera de hablarle a las gentes sobre cosas divinas, terminará estudiando teología y ordenándose sacerdote, posición desde la que ya podrá, por fin, evangelizar con total libertad. Cfr. Tellechea, J. I.: Ignacio de Loyola, solo y a pie, Sígueme, Salamanca, 1990.

68 Certeau, M. DE: La fable mystique, pp. 218 ss.

69 Certeau, M. DE: Le lieu de l'autre, p. 326.

70 La multiplicidad de nombres responde además, en este caso, a la propia variedad de teologías místicas, irreductibles a una sola denominación o a un solo contenido. Cfr. CERTEAU, M. DE: La fable mystique, pp. 189, 206.

${ }^{71}$ Ibíd., pp. 144ss. 
De esta forma, los místicos son un ejemplo perfecto del desplazamiento de las creencias y los modelos epistemológicos que se produce entre el s. XVI y el s. XVII. Están entre un «universo medieval» ${ }^{72} \mathrm{y}$ «el siglo de las Luces» ${ }^{73}$.

«Ellos pasan a la modernidad. Sin embargo, esta transformación se efectúa en el interior de un mundo que declina. Respeta globalmente el lenguaje religioso recibido, aunque lo trata de otra forma» ${ }^{74}$.

En la evolución de los místicos, situados en una verdadera encrucijada entre el pasado y el futuro, se ve con claridad cómo «una nueva forma epistemológica aparece en el umbral de la modernidad», cómo se genera «un nuevo espacio de saber» ${ }^{75}$. El discurso y la mentalidad que se expresan en las obras de los místicos son efectivamente nuevos y distintos a lo anterior, pero están construidos con los materiales del universo mental del que disponen, pues «una cultura es el lenguaje de una experiencia espiritual» ${ }^{76}$.

La fuerza de esta afirmación certeauniana ha de retumbar necesariamente en los oídos de cualquiera que haya querido aproximarse con sinceridad al estudio de la historia de la espiritualidad, en cualquiera de sus concreciones, pues pone en cuestión las afirmaciones absolutistas que llevan a soslayar los aspectos históricos de la evolución de cualquier realidad humana. Los místicos piensan y sienten en el mismo marco cultural que sus contemporáneos y no son esencialmente distintos a ellos (de hecho, por poner solo un ejemplo, también Descartes, coetáneo de tantos grandes místicos, emprende caminos nuevos en los campos de la ciencia y la filosofía ${ }^{77}$ ). Aplicándose a sí mismo y sus contemporáneos jesuitas esta máxima, Certeau utilizará una expresión que abre el camino a la orientación fundamental desde la que nuestro autor enfoca la mística y su relación con el conocimiento: el lenguaje.

«Nosotros hemos aprendido el lenguaje de nuestro tiempo, participamos de su mentalidad $»^{78}$.

Toda persona y todo grupo humano construye su espiritualidad, su pensamiento y su discurso con los elementos conceptuales y lingüísticos que su momento histórico le ofrece, aunque, y esto es lo más importante, no tiene porqué combinarlos y utilizarlos de la misma forma en que lo han sido hasta entonces. No será, por tanto, el contenido en sí de las afirmaciones y de los planteamientos de los místicos lo que suponga una revolución respecto a los siglos precedentes, sino, más bien, el modo, la forma diferente en que se articulan para configurar un discurso los mismos elementos de antaño, en suma, «un tratamiento distinto de la tradición cristiana» ${ }^{79}$. La prioridad atribuida a este otro uso posible de los mismos elementos lingüísticos (conceptuales, espirituales, litúrgicos, etc.) sitúa el análisis de Certeau en el campo de la enunciación, que «se distingue de la ordenación objetiva de los enunciados» ${ }^{80}$ y donde «una nueva epistemología se impone, lingüística» ${ }^{81}$.

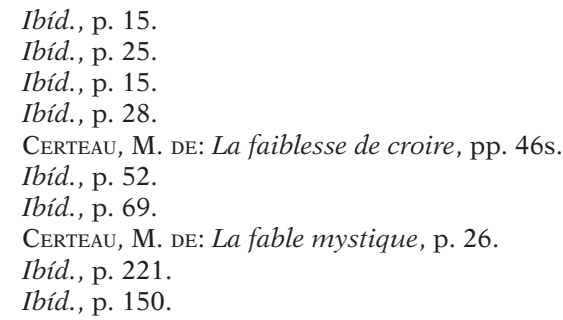


La orientación enunciativa de la perspectiva certeuniana aporta grandes ventajas al estudio de la mística ya que no entra, como hiciese la teología oficial de su tiempo, en una discusión acerca de los contenidos, sino que se mantiene en el campo del uso que los místicos hacen del lenguaje. Además esta orientación ayuda también a poner a la mística en relación con la otra nueva teología de los s. XVI y XVII, la llamada teología positiva o bíblica, dedicada a recuperar también la voz de Dios, aunque, en este caso, a través de un retorno a las fuentes de la Palabra: las Escrituras. En palabras de Certeau, "una epistemología de la enunciación aproxima las dos teologías modernas» ${ }^{82}$, distinguiéndolas de una escolástica silogística y puramente intelectual, ajena a toda idea de conversación con Dios.

\subsection{Una ciencia experimental}

Si algún cambio respecto a la teología clásica supone esta orientación conversacional, enunciativa, de la búsqueda de Dios que emprenden los místicos, es el cambio de método que supone en el abordaje de la pregunta por la verdad y esto incluso en relación a la mística previa. Y es que sería iluso pensar que los místicos, por más que se adentren en el terreno de la paradoja, han dejado de lado la idea de verdad y su persecución. Para ellos, como ejemplifica muy bien el místico certeauniano por antonomasia, Jean-Joseph Surin, no se trata de desarrollar un gran repertorio de palabrería espiritual, sino de construir una verdadera ciencia mística.

Si la ciencia es algo que está siempre en marcha en relación con una verdad, aquello que se entiende por verdad será fundamental para definir la ciencia y sus métodos. Por eso es tan importante que en Surin, y en otros muchos místicos, la concepción de Dios como alguien con quien se establece una relación se imponga a la de Dios como algo que puede conocerse de un modo puramente intelectual. Esta convicción desplaza la investigación sobre lo divino y su relación con la humanidad desde el ámbito del intelecto al de la experiencia, término clave en esta cuestión. Frente a un discurso abigarrado de sentencias y silogismos, los nuevos místicos recurrirán a la autoridad de aquellos que han experimentado a Dios, oponiendo "de mil formas una "ciencia de los santos" a la escolástica de los teólogos profesionales» ${ }^{83}$. Refiriéndose al uso que Surin hace de San Juan de la Cruz en sus escritos, Certeau dirá que «Surin, polemista y cruzado de la mística, recurre a los santos contra los ataques de los "filósofos". Busca, a través de ellos, defender una "ciencia" contra las "máquinas de una teología" »".

Pero estas máquinas, bien engrasadas por siglos de predominancia sin oposición, no podían dejar que estos peligrosos innovadores pusiesen en peligro la tradición sin intentar, al menos, desautorizarles. Dos alternativas básicas podían emprenderse para negar la afirmación de que a Dios se le conoce por la experiencia más que por la elucubración: la puesta en duda del carácter personal de Dios (incompatible con los propios principios del cristianismo) o cuestionar la posibilidad del ser humano de tener una experiencia real de las cosas divinas. Será en este segundo terreno donde el enfrentamiento entre uno y otro bando tenga lugar. De hecho, al abordar la mística desde un punto de vista epistemológico, puede verse como uno de los aspectos centrales del cuestionamiento que hace del saber teológico tradicional es la corrección del planteamiento que tenía éste sobre las posibilidades de percepción de lo sobrenatural.

82 Ibid., p. 146.

83 CERTEAU, M. DE: L'Absent de l'histoire, p. 50.

84 Ibidem. 
Certeau expone los detalles de esta colisión entre antiguos y modernos a propósito del enfrentamiento entre Surin y Jean Chéron, un carmelita que defenderá «la impermeabilidad de la conciencia a lo sobrenatural, justificada por la concepción de un orden de la gracia sobreañadido al de la naturaleza ${ }^{85}$. Hipótesis conservadoras como esta (que como dirá nuestro autor, «no son especialmente favorables a una inteligencia teológica de la vida espiritual» ${ }^{86}$ ), buscan contradecir a la mística en su término clave: la experiencia.

«Finalmente, subyacente a estas argumentaciones, vuelve por todas partes la idea de que lo sobrenatural, en sí, escapa a toda percepción y que, solo, lo «natural» es susceptible de experiencia» ${ }^{87}$.

Pasados solo algunos años, con algunos acentos cambiados pero reconocible en el fondo de las cuestiones en liza, en la discusión teológica entre Chéron y Surin se actualiza la controversia de auxiliis que hiciera célebres a Báñez y Molina en el siglo xvi. Para Certeau, en el siglo XVII, "la mística es un lugar de discordia donde regresa, pero en función de la experiencia cristiana, "la interminable y omnipotente cuestión de la gracia”. Ella pone simultáneamente en cuestión el rol de la experiencia en relación a las instituciones doctrinales (es decir, el carácter eclesial de la verdad) y la relación entre lo natural y lo sobrenatural» ${ }^{88}$.

De esta forma, queda patente que en la cuestión de la experiencia radica toda la acreditación del discurso místico ${ }^{89}$. La experiencia directa de lo divino es para los místicos (veánse los ejemplos, entre muchos otros, de S. Ignacio de Loyola o S. Teresa de Ávila ${ }^{90}$ ), una de las dos vías de salida a la crisis de credibilidad del cristianismo tras la división de la cristiandad producida por la Reforma protestante. La otra es «una definición eclesiástica o catequética de la verdad $»^{91}$, que para muchos de ellos no deja de ser un esfuerzo por sustituir con la autoridad de la institución la verdadera autoridad divina, ausente. Por ello, los místicos emprenden una "cruzada hacia el interior ${ }^{92}$, se retiran hacia un refugio donde puede seguir teniendo espacio una vida de $\mathrm{fe}^{93}$, donde puede esperarse aún encontrar la presencia de Dios en toda su verdad.

«En el interior mismo de las Iglesias, una espiritualidad o una mística en busca de un lenguaje se desconecta poco a poco de una administración metódica de los comportamientos y los espectáculos religiosos. Ahí se agrava la separación que, desde el s. XvI, afecta a la articulación esencial del hacer y el decir: el sacramento» ${ }^{94}$.

Uno de los maestros en el uso místico de la experiencia es Ignacio de Loyola. En la exploración científica del interior de cada cristiano su metodología del discernimiento (condensada en los Ejercicios Espirituales), supone un antes y un después, y una vía de profundización espiritual que muchos místicos aprovecharán con especial avidez. El discernir ignaciano se basará en el análisis detallado de lo que ocurre en la vida del cristiano y de los ecos que suscita en su espíritu esto que ocurre, buscando la identificación

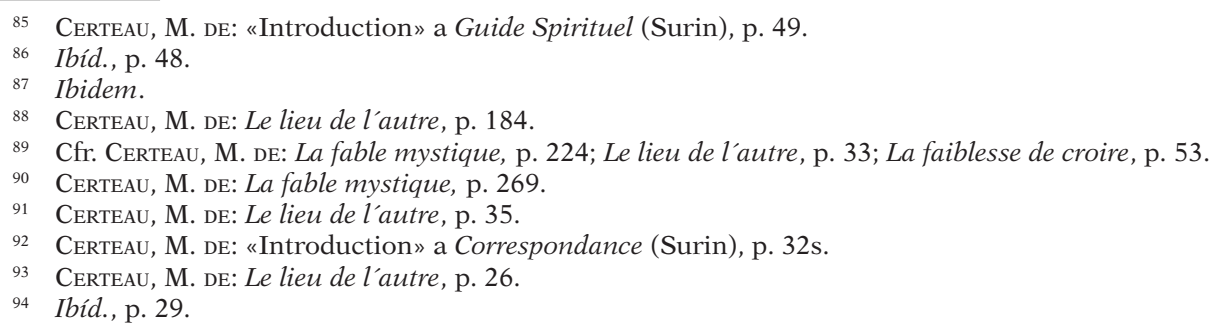


de la voluntad de Dios y la vivencia de su presencia real en el mundo. Es algo, como puede verse, muy parecido a lo que persigue la mística en general, por lo que ambas cosas, mística y discernimiento se darán de la mano en numerosos jesuitas, como en Pierre Favre: «Que cada aspecto de la experiencia sea referido al movimiento profundo que la funda, es lo que ha percibido el discernimiento; pero es también lo que atestigua su carácter místico» ${ }^{95}$.

Como tantos otros antes y después de él, pero con una profundidad inusitada, JeanJoseph Surin se consagrará también al estudio de la experiencia de Dios en su propia vida y en la de los demás. Según Certeau, «la lucidez es en él inteligencia de la experiencia: discierne, de una forma cada vez más aguda, lo verdadero de lo falso ${ }^{96}$. Podría decirse con propiedad que «emprende una "ciencia experimental" de la vida espiritual» ${ }^{97}$. La orientación total hacia la experiencia se convierte en Surin en el nuevo método científico que ha de llevar al conocimiento de Dios, por lo que otros elementos vitales se hacen protagonistas en detrimento de los razonamientos, entre ellos, la voluntad y las prácticas.

Respecto a la primera, es preciso remitirse a lo que Certeau llamará la centralidad del volo (del querer), algo que va totalmente a contramano con las reflexiones epistemológicas habituales: que la posibilidad del conocimiento no descansa ya sobre la inteligencia, sino sobre la voluntad ${ }^{98}$. Aspecto señalado por S. Ignacio y por Surin, entre otros, la relevancia de la voluntad para llegar a conocer a Dios, rompe el reparto clásico de las posibilidades del conocimiento, abriendo puertas a muchos que por su educación (más bien su falta de ella) o sus condiciones mentales y/o sociales, no eran considerados capaces de llegar a Dios. Aunque esta nueva vía deja claro que el acceso a Dios sigue sin ser para todos ${ }^{99}$, la restricción no estará ahora en condicionamientos ajenos o externos a la persona, sobre los que esta no puede influir. El nuevo eje se sitúa en la voluntad, el centro de la persona, donde ésta se juega el acceso a la sabiduría de Dios y donde se concentrará todo el esfuerzo metodológico de la ciencia mística.

«No se elige ser creyente. Es un querer que atraviesa las opciones y del que éstas no son más que los síntomas. Fundamentalmente, ser creyente, es querer ser creyente» ${ }^{100}$.

Analizado desde las categorías lingüísticas certeaunianas, el volo, el querer místico, es el discurso performativo extremo ${ }^{101}$ : con su expresión crea una realidad. Solo cuando la persona expresa la voluntad firme y decidida de encontrarse con Dios es posible que tenga en su vida las experiencias que han de llevarla al conocimiento verdadero de la divinidad. Como diría Unamuno, «creer en Dios es, en primera instancia [...] querer que haya Dios, no poder vivir sin Él» ${ }^{102}$. Visto en una perspectiva evangélica, solo el seguimiento permite el conocimiento, como se expresa en aquel diálogo en que Jesús, a la pregunta general y preñada de significado de los discípulos de Juan Bautista (que en adelante le seguirán a él) «Rabí — que significa maestro— ¿dónde vives?», responde con un «Venid y ved» ${ }^{103}$, que condiciona el conocimiento al recorrido de un camino que

95 Certeau, M. DE: «Introduction» a Mémorial (Favre), p. 95.

96 Certeau, M. DE: «Introduction» a Guide Spirituel (Surin), p. 22.

97 Ibidem. Cfr. La fable mystique, p. 166.

98 Ibid., p. 227.

99 Ibíd., p. 246.

100 Certeau, M. DE: La faiblesse de croire, p. 288.

101 Certeau, M. DE: La fable mystique, p. 238.

102 Unamuno, M. DE: Sobre el sentimiento trágico de la vida, p. 182.

103 JUAN 1, 38-39. 
solo puede iniciarse voluntariamente. De esta forma, radicado en un ejercicio voluntario de la libertad personal, «el discurso místico abre el campo de un conocimiento diferente» ${ }^{104}$.

«Es un querer quien instaura un saber. Un conocimiento no se hace posible más que por una decisión primera: quiero» ${ }^{105}$.

En lo que hace al segundo de los elementos que se han mencionado, las prácticas, para los místicos se van convirtiendo en un elemento esencial de búsqueda de lo divino y de expresión de esa voluntad a la que se ha hecho referencia. Certeau señalará que esto se debe a que "la experiencia se inviste en las prácticas: prácticas sociales o técnicas en el "exterior", prácticas de piedad en el "interior" »106. Esta relevancia central atribuida a las prácticas explica que muchos grandes místicos sean al tiempo los reformadores clave de sus entornos eclesiales (S. Teresa, S. Juan de la Cruz, S. Ignacio, etc.). De su experiencia de Dios brotan nuevos caminos, tanto exteriores como interiores, para vivir una fe.

Como anotaciones finales, hay que destacar que en Surin, como en los demás místicos, ya el hecho de prestar atención al método es signo de un cambio de mentalidad, de una evolución desde el paradigma de la perdurabilidad puramente medieval (donde el valor supremo fuera el orden y la estabilidad), hacia un modelo moderno de pensamiento organizado en torno a la rapide ${ }^{107}$ (donde conceptos como productividad y utilidad desplazan a los anteriores). Además, el cambio de método, que deriva de y desemboca en un cambio de la concepción que de sí mismos tienen los místicos en tanto que grupo, ayudará a ir cohesionándolos entre sí a raíz de la utilización de estas nuevas maneras, que los identifican separándolos de los otros. Como señala con insistencia Certeau, la aplicación del "procedimiento debe producir el saber y modelar el grupo», pues «en proporciones variables, el método combina acciones sobre las cosas con acciones sobre los interlocutores (discípulos, corresponsales, lectores). Fabrica lo social al mismo tiempo que el saber» ${ }^{108}$.

Vistos ya el cambio de premisas y de método en los que se basa la ciencia experimental de los místicos, préstese atención ahora al lenguaje que produce, elemento fundamental en el que se enmarca la conversación con Dios. El discurso es la piedra de toque de la mística desde la perspectiva certeauniana, pues «la nueva ciencia se define como un lenguaje. Es, desde un primer momento, una práctica del lenguaje [...] la mística es una "manera de hablar" ${ }^{109}$.

El conversar místico ${ }^{110}$ pone el lenguaje en el centro de la escena, ya que la pregunta principal de la mística es acerca de la posibilidad de una comunicación con Dios. Como dirá Certeau, «la cuestión esencial concierne a la posibilidad de escuchar y de hacerse escuchar»111, por lo que toda la mística está atada a una dimensión comunicativa que atraviesa la espiritualidad de cuño judeocristiano (que afirma que existe un Dios que ha

104 CERTEAU, M. DE: La fable mystique, p. 236.

105 Ibíd., p. 230.

106 Certeau, M. DE: Le lieu de l'autre, p. 188. Aplicándose a sí mismo esta reflexión, ya había afirmado con anterioridad que «la experiencia cristiana existe únicamente cuando se inscribe en prácticas y en un lenguaje», El estallido del cristianismo, p. 70.

107 Certeau, M. DE: La fable mystique, pp. 176ss.

108 Ibid., pp. 176s.

109 Ibid., p. 156.

110 Ibid., pp. 216ss.

111 Ibid., p. 14. 
hablado a la humanidad), por oposición a la de origen grecolatino (basada en el silencio de los dioses).

Además, el momento en que surge la mística a la que nos estamos refiriendo está marcado por varios hechos que generan en muchos la sensación de la pérdida de un lenguaje común y el inicio de una época de confusión. El progresivo abandono del latín, hasta entonces lenguaje unificador de Occidente, inaugura un bilingüismo (latín/lenguas vulgares) que introduce la confusión en Europa ${ }^{112}$. También la imprenta, pese a su capacidad para difundir las letras, tiene como consecuencia el que «los textos escapan a la institución universitaria y a la interpretación magisterial ${ }^{113}$, rompiendo la unificación doctrinal del medievo. En este mismo sentido, la traducción implica un cambio de perspectiva mental ${ }^{114}$, que agudiza el proceso de fragmentación del saber y de la fe. Ante la orfandad creada por esta situación en que la comunicación se ha roto y ya no tiene credibilidad $^{115}$, aparece «el proyecto místico de unificar el conocimiento en un nuevo lenguaje» ${ }^{116}$, pues «la mística es el anti-babel» ${ }^{117}$.

Pero, ¿con qué reponer un lenguaje caduco? Abandonado ya el discurso escolástico, embriagado de un deseo de precisión, los místicos hablarán de las cosas de Dios con palabras antiguas, pero con significados nuevos. Se da un cambio del lenguaje místico medieval de referencia por otro basado en lo corporal, en lo experiencial, donde las cartas y diarios priman frente a los manuales de otrora ${ }^{118}$, y lo personal y vivencial ganan terreno frente a lo puramente intelectual, de forma que «la experiencia mística tiene así, a menudo, el aire de un poema» ${ }^{119}$.

«No se trata, como en una teología, de constituir un conjunto particular y coherente de enunciados articulados en base a los criterios de «verdad» aportados por la triple instancia de una Escritura, de un Magisterio y de una práctica creyente mayoritaria [...] Es cuestión de tratar el lenguaje común (el de todo el mundo y el de "no importa quién", y no el de disciplinas técnicas) en función de su posibilidad de ser hablado» ${ }^{120}$.

Es un paso más en el proceso de «desontologización del lenguaje» ${ }^{121}$, que arranca en la Edad Media y que va minando poco a poco la capacidad del lenguaje para presentarse como un reflejo acabado de lo real. Unido a los místicos en este nuevo uso del discurso, esta cuestión de la adecuación del lenguaje a lo real será en todo momento central para Certeau, quien asumirá con todas sus consecuencias la perspectiva de la enunciación, desde la que concluye que «dos siglos de análisis lingüístico han mostrado que el lenguaje no expresa las cosas, no les da presencia y no es la transparencia de un mundo, sino que es un lugar organizado que permite las operaciones ${ }^{122}$.

112 Ibid., p. 169.

113 Ibid., p. 162.

114 Ibid., p. 164.

115 Ibid., p. 217.

116 Ibid., pp. 169, 175.

117 Ibid., p. 216.

118 Es destacable aquí la relevancia adquirida por la escritura de cada uno de los místicos, que desacata el respeto reverencial a las autoridades tan preciado a la teología medieval, donde la disponibilidad del Libro de las sentencias de Pedro Lombardo, la Summa theologiae de Tomás de Aquino y de algunas obras eminentes más, hacían innecesaria para el sabio la escritura de una obra propia. Ahora, por el contrario, «el santo que se convierte en místico recibe una función escrituraria. Se instala en el campo del lenguaje», Ibíd., p. 139.

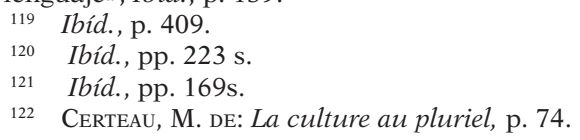


Tomar conciencia de esta realidad operatoria del lenguaje implicará necesariamente dejar de lado cualquier pretensión de que este sea un reflejo exacto de la realidad, introduciendo a quién así lo asuma, en el ámbito de la interpretación y de una comunicación siempre incompleta. Resaltando, en esta línea, la distorsión que todo lenguaje entraña respecto a lo que quiere expresar, Certeau señalará que al acercarse a la mística no conviene nunca perder de vista que «toda experiencia espiritual que se expresa, desde que se expresa, se encuentra, de alguna forma, "alienada" en el lenguaje» ${ }^{123}$.

En este sentido, el gusto místico por la paradoja es una magnífica expresión de las claves de la nueva ciencia, que implica un cambio de lógica respecto a la teología anterior. Aunque el cambio de la metodología científica no es, ni con mucho, algo exclusivo de la teología en la época que nos ocupa, sino que afecta al conjunto de las disciplinas del saber durante todo el siglo XVII, (cuando "la ciencia impone sus criterios a todos, creyentes o no» ${ }^{124}$ ), el uso de la paradoja sí que es, de hecho, el rostro de una de las rupturas fundamentales de la mística con la teología previa: la predilección mística por una lógica en la que caben los contrarios. Esta será, según Certeau, una nueva lógica narrativa, la tierra del oxímoron ${ }^{125}$, donde la coincidentia oppositorum ${ }^{126}$ se convierte en un referente esencial, reflejando el cambio de paradigma que conecta a la mística con otras corrientes de pensamiento de mil lugares y tiempos, por su negación de los principios fundamentales de la lógica clásica: el principio de contradicción y el principio de tercio excluido.

El uso de la paradoja saca a los místicos de un mundo de significados estables para introducirlos en un espacio conceptual donde lo relevante es el uso de los significantes para dar lugar a la expresión de las experiencias. Ya no es tan importante qué se hace sino cómo se hace ( «el proceso de fabricación» ${ }^{127}$ ), algo que resume muy bien la noción de estilo, y que es la clave del nuevo método místico. Muy querida a Certeau, esta noción de estilo es absolutamente central en La fable mystique ${ }^{128}$, donde se condensa en la importancia dada a los modos o «maneras de proceder», que expresan la existencia de una «episteme distinta a la nuestra» ${ }^{129}$.

123 Certeau, M. DE: L'Absent de l'histoire, p. 44.

124 Certeau, M. DE: L'écriture de l'histoire, pp. 163ss.

125 Certeau, M. de: La fable mystique, pp. 198 s., 272.

126 Esta expresión (con sus variantes: coindidatio, complexio, etc.) aparece prácticamente en todas las obras de Certeau. Veánse, solo a modo de ejemplo: CERTEAU, M. DE: La faiblesse de croire, pp. 216, 221; "Introduction» a Correspondance (Surin), p. 55; L'Absent de l'histoire, pp. 63s.; "Introduction» a Guide Spirituel (Surin), p. 38; L'écriture de l'histoire, p. 373; Le lieu de l'autre, p. 51; L'invention du quotidien.1. Arts de faire, p. 139.

127 CERTEAU, M. DE: La fable mystique, p. 195.

128 Véase como, incluso sin realizar una búsqueda exhaustiva, la citación de esté término es amplísima en esta obra, CERTEAu, M. DE: La fable mystique, pp. 26, 38, 131, 135, 151, 153, 157, 164, 201, 202, 205, 216, 219, 229, 349, 408; así como en otras de Certeau: L'Absent de l'histoire, pp. 42, 54, 57, 59, 68, 69; ; L'invention du quotidien.1. Arts de faire, pp. 78, 121. Como una de las fuentes de que bebe nuestro autor en esta cuestión, Luce Giard hace referencia (GIARD, L.: "Cherchant Dieu», p. 16), a la obra de Granger, G-G.: Essai pour una philosophie du style. Nuestro autor llegará a señalar a esta noción de estilo como un posible identificador del conjunto de la práctica cristiana cuando, abordando el modo en que los cristianos se implican en la vida social, afirma que «un espíritu cristiano se inscribe en las tareas sea por la motivaciones (militancia, testimonio, etc.) sea por una moralización de las conductas (abnegación, generosidad, perdón, etc.), sea finalmente por la elección de tareas privilegiadas (hay una topografía posible de reutilizaciones de militancias cristianas en la enseñanza, el periodismo, la animación cultural, la asistencia social o sanitaria, etc.). Estos diversos elementos constituyen un "estilo". Existe un "perfil" cristiano", CERTEAU, M. DE: La faiblesse de croire, pp. 278s.

129 Certeau, M. DE: La fable mystique, p. 83. 
«Una metamorfosis cambia el estatuto de los términos sin cambiar su singularidad fenoménica. Un mundo distinto se insinúa en los mismos signos» ${ }^{130}$.

\subsection{La dimensión política de la mística: herejías}

Después de todo lo leído hasta aquí, no cabe dudar del modo en que están profundamente imbricados lo epistémico y lo social en la realidad de cualquier ciencia (y de cualquier fenómeno humano). Tampoco en el caso de la mística estas dos dimensiones están alejadas, y al dar cuenta del alcance que esta «ciencia experimental» tiene en la dinámica política de la vida eclesial de los místicos, Certeau no hace más que señalar de nuevo la pertinencia de su planteamiento. Los místicos, además de romper los corsés del conocimiento tradicional sobre Dios, abren también un nuevo ${ }^{131}$ lugar para la vida religiosa, un espacio intermedio entre convicciones absolutas y opuestas, las más de la veces llamado herejía.

La acusación de ser herejes es algo común a la historia de muchos místicos, tanto que pareciera ir cosida a sus ropajes. Para aproximarse a esta realidad, no menos frecuente que dolorosa para muchos de sus afectados, Certeau se hará eco de diferentes estudios anteriores relativos a la historia religiosa europea. En ellos constata que los historiadores, por diversos motivos, se han centrado en los fenómenos heréticos más que en los ortodoxos, lo que no siempre permite dar una visión ajustada de estos en el conjunto de la historia religiosa ${ }^{132}$.

De entre las fuentes solventes consultadas por Certeau, dos referencias destacadas pueden citarse aquí para señalar dos aspectos diferentes de la misma cuestión: la relación de las instituciones con los místicos a los que se acusa de herejes y viceversa. De un lado, Certeau citará a uno de sus maestros, Alphonse Dupront, que había identificado la herejía como uno de los puntos capitales de la historia religiosa de los ss. XVI y XVII ${ }^{133}$. En torno a las reflexiones de Dupront sobre la evolución y el desarrollo de la herejía en esa época, nuestro autor pone el acento en la importante transformación que supone el que «los principios se relativicen y se inviertan», produciendo que la pertenencia (estrictamente social, práctica) a una institución eclesial, pase a ser más importante que los contenidos de la fe para asegurarse la certidumbre de las «verdades propias a cada uno» ${ }^{134}$.

Luego es la práctica, y no el principio religioso que se supone que la sostiene, la que provee de la identidad eclesial necesaria para no ser candidato a la herejía. La herejía aparece así "como una división social y una producción ideológica» ${ }^{135}$, que refleja la realidad de una sociedad escindida por mil cuestiones ajenas a la religión, pero que aprovecha a esta para escenificar sus enfrentamientos.

«La herejía se presenta, en efecto, como la legibilidad social de un conflicto social y como la forma misma, binaria, del modo en que una sociedad se define excluyendo aquello de lo que ésta ha hecho su otro» ${ }^{136}$.

130 Ibíd., pp. 82s.

131 Téngase en cuenta que, en esta época, "quien dice "nuevo", dice sospechoso», Certeau, M. DE: $L e$ lieu de l'autre, p. 171.

132 Certeau, M. DE: L'écriture de l'histoire, pp. 51ss.

133 Ibíd., p. 156.

134 Ibidem.

135 Certeau, M. DE: La fable mystique, p. 31.

136 Certeau, M. DE: Le lieu de l'autre, p. 23. 
Por eso los místicos, consagrados a su nueva ciencia experimental y, por tanto, a nuevas formas de poner por obra su fe, se sitúan por su propio caminar en una zona al margen de la mayoría, fronteriza, que quiebra su inmediata identificabilidad con una $u$ otra ortodoxia. Una u otra porque este fenómeno se da en todas y cada una de las tradiciones religiosas que atraviesan periodos de importante relevancia institucional. Así, diferentes místicos de distintas tradiciones religiosas «se distinguen mucho menos por la naturaleza de su experiencia que por el hecho de pertenecer a grupos contrarios» ${ }^{137}$. Muchas de sus trayectorias son tremendamente similares entre sí y suelen compartir el ser mal vistos por sus respectivas organizaciones religiosas, argumentando Certeau que «a menudo reciben el trato común de ser sospechosos (tanto ante ellos mismos, como ante su religión) porque traicionan, en nombre de una interioridad, las instituciones tradicionales de su sociedad» ${ }^{138}$.

En el caso de los místicos católicos de los siglos XVI-XVII, la acusación de herejía tampoco será una rareza. Frente al planteamiento místico, compartido por el protestantismo al menos en parte ${ }^{139}$, que supone la posibilidad individual de acceso a Dios (y por tanto, a la verdad), cierta corriente tradicionalista e institucionalista en el catolicismo defenderá la imposibilidad para el ser humano de «reconocer la verdad», lo que en el fondo es la afirmación de la imprescindible necesidad de la institución para poder acceder a ella ${ }^{140}$.

Pero la mística o el místico no pueden sustraerse a la fuerza que les impele a salir de lo establecido. Romper con ello forma parte de su más íntima realidad religiosa, de forma que para Certeau "se convierte en "místico" el que se separa de la institución"141, siendo esta separación un hecho cuya necesidad extiende nuestro autor a toda religiosidad sincera, pues «la ruptura es una constante de la espiritualidad [...] La ruptura no es un elemento aislable en el lenguaje necesariamente colectivo de la espiritualidad. Pertenece al "estilo" de este lenguaje» ${ }^{142}$.

En el reverso de la relación institución-místico, se perfila un tipo de discurso que, con mayor o menor voluntariedad por parte de cada místico o mística, ataca la estabilidad de la institución en que está incardinado. En este sentido es destacable la referencia continuada e intensa por parte de Certeau a la obra de Leszek Kolakowski, Cristianos sin iglesia, que se centra en la cuestión de las herejías desde la perspectiva de la dimensión política de las creencias ${ }^{143}$. Certeau toma muy en serio este trabajo histórico aunque, eso sí, sin dejar de hacer notar la vinculación de los resultados de Kolakowski con el lugar social desde el que los produce, llegando a afirmar que «intenta hacer una historia marxista de las ideas» ${ }^{144}$ o que "hace" la historia, en el sentido de que quiere producir un "modelo" de inteligibilidad histórica» ${ }^{145}$. En esta obra, el pensador polaco trataría «sobre el cristianismo no confesional del s. XVII, es decir, sobre la oposición a la

137 Certeau, M. DE: L'écriture de l'histoire, p. 158.

138 Ibidem.

139 Sobre la estrecha vinculación entre mística y herejía luterana en la España de los siglos XV y XVI, cfr. entre muchos otros, Pastore, S.: Una herejía española, trad. de Clara Álvarez Alonso, Marcial Pons Historia, Madrid, 2010.

140 Certeau, M. DE: La fable mystique, p. 137.

141 Ibid., p. 116.

142 Certeau, M. DE: La faiblesse de croire, p. 54

143 Certeau, M. DE: L'Absent de l'histoire, p. 109

144 Ibidem.

145 Ibid., p. 110. 
subordinación de la conciencia religiosa a las estructuras hierocráticas», lo que podría ser llamado también «una sociología del antiinstitucionalismo» ${ }^{146}$.

La lectura antiinstitucional de la realidad mística, sin dejar de ser interesante, pone mayor voluntariedad en la animadversión de los místicos hacia la institución de lo que parece aconsejable. De los estudios certeaunianos se colige que en muchos casos, la postura contraria a lo establecido de los místicos no parece tratarse tanto de una decisión de sustituir una institución por otra, cuanto de una consecuencia, poco querida pero aceptada, del choque entre la sinceridad en la vida y en el discurso por parte del místico y el afán de conservación por parte de la institución. El hecho es que, como ha notado Certeau, «situándose en una posición distinta a la enseñanza magisterial, [los místicos] pretenden sin embargo dar testimonio del mismo Dios que aquella ${ }^{147}$, lo que necesariamente establece una dualidad de posibilidades de dar razón de la verdad: la institucional y la de la mística. En la medida en que se afirme que existe una única verdad sobre lo divino, esta dualidad implica acusar de falsedad a una de estas dos entidades. En el contexto de un durísimo ensayo sobre la tortura, Certeau lo plantea con crudeza.

«El ajeno o el rebelde a la institución testimonia una ambición que no es tolerable (sino hipócritamente): en efecto, de una manera u otra, plantea en un discurso - político (un proyecto revolucionario), religioso (una intención reformista), véase analítico (una palabra "libre") - el poder de rehacer la institución. A esta pretensión de reconstruir el orden de la historia a partir de una palabra "contestataria", la tortura opone la ley de la institución ${ }^{148}$.

Tortura física presente en muchos de los casos más severos de acusaciones de herejía, aislamiento social en los más leves. De una forma o de otra la institución manifiesta su rechazo a la innovación que el místico representa. Para poder comprender la dinámica en que se produce este rechazo en esta época en concreto, es clave tener en cuenta que «hay un trazo fundamental del s. XVII, a la vez religioso y cultural: una no-visibilidad del sentido (o incluso de Dios) ${ }^{149}$. Como marco de los discursos de renovación de la vida religiosa privada y colectiva que enarbolan los místicos, durante el transcurso de los siglos a que venimos haciendo referencia, Europa se transforma disolviendo la estructura de la cristiandad y entrando en una efervescente creación de nuevos estados nación. Esto supone un condicionante clave para la espiritualidad de un tiempo y un lugar.

«En la cristiandad rota en pedazos, [los místicos] tienen la experiencia de una defección fundamental, la de las instituciones de sentido. Viven la descomposición de un cosmos y se convierten en exiliados [...] Una permanencia referencial falta. Con la institución, opaca reserva del creer y del hacer creer, sus seguridades tácitas se desmoronan. Buscan un suelo. Pero finalmente las Escrituras aparecen tan "corruptas" como las Iglesias. Las unas y las otras están igualmente deterioradas por el tiempo ${ }^{150}$.

Por ello, los místicos se ven abocados a la creación de nuevos lugares a partir de las ruinas que quedan ${ }^{151}$; lugares que, indefectiblemente, pueden ser acusados de ser alternativas a la Iglesia. Cada una de las nuevas construcciones eclesiales que se levantan

46 Ibid., p. 109.

147 CERTEAU, M. DE: La fable mystique, p. 248.

148 CERTEAU, M. DE: Histoire et psychanalyse entre science et fiction, p. 229.

149 Certeau, M. DE: L'écriture de l'histoire, p. 167.

150 Certeau, M. DE: La fable mystique, p. 42.

151 Ibid., pp. 212-215. 
sobre las ruinas de la cristiandad, es también expresión de un éxodo ${ }^{152}$. Éxodo que supone un cambio de la comunidad eclesial-política de referencia y que se configura en el pensamiento de Certeau como una idea clave de la mística. Hasta el punto en que nuestro autor identificará al movimiento como la condición definitoria de la misma en la última página de La fable mystique.

«Es místico aquel o aquella que no puede dejar de marchar y que, con la certidumbre de aquello que le falta, sabe de cada lugar y de cada objeto que no es eso, que no se puede residir aquí ni contentarse con esto» ${ }^{153}$.

La figura de Jean Labadie (1610-1674), «el nómada», expresa con claridad este peregrinar consustancial a la mística ${ }^{154}$. En este personaje, al que Certeau trata con cariño («héroe barroco» ${ }^{155}$ lo llama), se hace carne «el movimiento de partir sin cesar» ${ }^{156}$ que caracteriza el itinerario físico, conceptual y espiritual, de tantas y tantos místicos. Para él "creer, es "venir" o "seguir" (gesto marcado por una separación), salir del lugar propio, ser desarmado por este exilio fuera de la identidad y del contrato» ${ }^{157}$. De afán polémico (un rasgo que sería también aplicable a Jacques Lacan, otro personaje fundamental para Certeau), a Labadie «su rechazo le supone mayor garantía que su aceptación» ${ }^{158}$. Por eso permanentemente sale y entra de diferentes grupos y confesiones. «Jesuita, jansenista, calvinista, pietista, quiliasta o mileranista, finalmente "labadista" ${ }^{159}$, en su vivir el viaje exterior está conectado esencialmente con un viaje interior ${ }^{160}$, por lo que puede afirmar sin ambages que "cambiando de comunión, no he cambiado de vocación» ${ }^{161}$.

Para Labadie, por tanto, como para tantos otros, «la tentación es la fijación. Ahí donde Dios es revolucionario, el diablo parece conservador ${ }^{162}$. De ahí que, repasando su trayectoria, Certeau vea que «el gesto de dejar a los jesuitas no es en el fondo más que un efecto lógico de esta experiencia ${ }^{163}$, comprendiendo que nunca, sea como sea, puede el espiritual indicar sobre un mapa cual es la «localización del paraíso terrenal» ${ }^{164}$, sino que es el fundamento de su pasión y su vida la constante e infinita tarea de buscarlo.

El éxodo se convierte así en una necesidad para el espiritual, que le lleva a viajar incluso fuera de la propia sangre, como ha señalado Certeau a raíz del marranismo. Las relaciones entre la mística y la pureza de sangre, o incluso la raza ${ }^{165}$, son estudiadas por Certeau en La fable mystique, en torno a la noción de marranismo espiritual ${ }^{166}$, sugiriendo una perspectiva complementaria de la mística como un «efecto de la diferencia judía

152 Para ver la relectura freudiana que Certeau hace de este término tan importante para los místicos, cfr. Certeau, M. DE: L'écriture de l'histoire, p. 496 n. 26b: «El Éxodo [...] es nuestro punto de partida».

153 CeRTEAU, M. DE: La fable mystique, p. 411.

154 Véase el capítulo dedicado a Labadie en Ibíd., pp. 374-405.

155 Ibid., p. 374.

156 Ibid., p. 411.

157 Certeau, M. DE: La faiblesse de croire, p. 295.

158 CERTEAU, M. DE: La fable mystique, p. 386.

159 Ibid., p. 374.

160 Ibidem

161 Ibid., p. 378.

162 Certeau, M. DE: La faiblesse de croire, p. 60. El movimiento es inherente a la búsqueda del místico, pues «si se quiere responder a la voluntad de Dios, hace falta desde un principio renunciar a fijarle fronteras», «Introduction» a Guide Spirituel (Surin), p. 29.

163 Certeau, M. DE: La fable mystique, p. 381.

164 Certeau, M. DE: La faiblesse de croire, p. 59.

165 Certeau, M. DE: La fable mystique, pp. 38ss.

166 Ibid., pp. 350, 404. 
en el ejercicio de un lenguaje católico» ${ }^{167}$. Esta idea nos lleva de vuelta al principio de este trabajo, insistiendo en la noción de uso de los elementos de un lenguaje frente a la importancia prestada anteriormente a los significados que forman estos elementos.

Para Certeau el uso de los mismos términos de la fe católica por parte de los conversos implica tener en cuenta el bagaje enunciativo que conlleva todo su sentir, su memoria y su vida espiritual, tan distinto necesariamente al de los cristianos viejos. Este uso muestra como «el modelo cultural del converso se difunde como el índice, fundamental, de una ruptura entre el lugar y el sentido» ${ }^{168}$.

Finalmente, es de justicia hacer notar cómo los estudios de Certeau sobre la mística dan paso a una forma distinta de entender la herejía (que no sería ya tanto el hecho de pensar algo distinto como de pensar que eso distinto es lo único correcto ${ }^{169}$ ); y a una forma de considerar al místico muy alejada de una actitud de condena, o ni tan siquiera de miedo o de sospecha generalizada. La predisposición de Certeau hacia ellos, francamente positiva, coincidiría sin apuros con la valoración que Gershom Scholem (a quién Certeau había leído con admiración ${ }^{170}$ ), hacía de los cabalistas judíos al escribir «que en realidad estaban muy lejos de ser heréticos y tan sólo buscaban profundizar el sentido de los conceptos» ${ }^{171}$.

La valoración integral que realiza Certeau de estos hombres y mujeres peregrinos de la fe, se refleja en su orientación general al estudiar la mística y también en las pequeñas anotaciones particulares con los que rescata las vidas de cada uno de ellos. Anotaciones llenas de cariño y respeto como cuando recordando a Surin y Labadie, escribe que son «dos de los más grandes escritores religiosos del siglo XVII, aventureros de genio, ciertamente muy diferentes, pero entonces reunidos por una misma urgencia de lo absoluto y a menudo confundidos por sus acusadores: Jean-Joseph Surin y Jean Labadie» ${ }^{172}$.

\section{Conclusión}

La interconexión entre creer y saber es una de las premisas básicas de la antropología del creer de Michel de Certeau. Tal y como muestra en sus estudios, ambas dimensiones son interdependientes e inseparables. La relación que mantienen, que no está exenta de conflictos, aparece a sus ojos como algo fundamental y necesario. Dentro de dicha relación el creer realiza una función de sostén, sirviendo como un suelo desde el que puede edificarse un saber que no ha de perder nunca la conciencia de su precariedad ni de los pilares en los que se sostiene.

Sin embargo, la precedencia del creer sobre el saber no le brinda al primero una patente de corso con la que erigirse en instancia superior respecto a los esfuerzos

167 Ibid., p. 40.

168 Ibid., p. 404.

169 Certeau, M. DE: La faiblesse de croire, p. 132. Puede verse una ampliación de la idea de herejía, hasta afirmar que todos somos herejes respecto al pasado, cuando Certeau escribe sobre «la herejía del presente», Ibíd., p. 82, que nace de la diferencia insalvable que existe entre nosotros y nuestros antepasados a causa de la premisa establecida anteriormente, que afirma que cada espiritualidad se forja con el lenguaje de una cultura.

170 Cfr. Ibíd., p. 11; La fable mystique, p. 37.

171 Scholem, G.: Conceptos fundamentales del judaísmo, p. 87.

172 Certeau, M. DE: «Crise sociale et réformisme spirituel au début du XVIIe siècle. Une "Nouvelle Spiritualité" chez les Jésuites français», en Problémes de vie religieuse: Le mépris du monde, Cerf, París, 1965, p. 131. 
epistémicos del ser humano. Antes bien, el creer que describe Certeau está atravesado de Evangelio, es decir, de la conciencia de su debilidad como condición básica desde la que poder decirse un creer cristiano.

Trayendo a colación los estudios certeaunianos sobre la mística de los siglos XVI y XVII, se han ido desgranando con mayor detalle estos distintos aspectos de la relación creer-saber. Asimismo se ha abordado la dimensión política de la mística resaltando el modo en que la institución, a través de la identificación de herejías, mantiene el control respecto de los saberes que se pretenden diferentes al saber oficial y, especialmente, respecto de las prácticas heterodoxas que se basan en dichos saberes. El creer de los místicos aparece aquí como la base sobre la que se construyen, a un tiempo, los nuevos saberes y las nuevas prácticas.

Universidad de Huelva

Juan D. GonzÁLEz-SANZ

orcid.org/0000-0002-4344-8353

juan.gonzalez@denf.uhu.es

[Artículo aprobado para publicación en noviembre de 2014]. 